\title{
Rye Cluster of Russia: Identification of Raw Material Area Based on the Localization Coefficient Technique
}

\author{
Kostenko O.V. \\ Faculty of Economics \\ Vyatka State Agricultural Academy \\ Kirov, Russia \\ kostenko_ov@vgsha.info
}

\begin{abstract}
In Russia, there are certain prerequisites for the development of the group of sectors for production and processing of rye in terms of clustering. This paper aims at identifying the territories of Russia of high localization of rye grain production and evaluating the level of this localization. The article presents the unexpectedly pronounced results obtained using the modified LC technique. A group of regions with very high LCs in rye grain production has been identified (from 3.5 to 12.0). In addition, these regions are also included in the Top10 Ranking of Russia regions by the gross harvest of rye grain. Of the total set of regions with high LCs of rye production, a priority is given to the regions forming a compact territory. The article substantiates that the raw material base of the rye cluster in Russia can be comprised of 10 regions of the Volga Federal District. Total, these regions create $2 / 3$ of the gross harvest of rye grain in Russia and $\mathbf{8 0 - 9 0 \%}$ of sales of rye grain in interregional markets.
\end{abstract}

Keywords — cluster; cluster identification; modified localization coefficient; rye; Volga Federal District.

\section{INTRODUCTION}

An economic policy to support clusters (cluster policy) should be based on characteristics of a cluster as a system. It is known that clusters arise as a result of self-organization processes, as a consequence of the objective aspiration of companies to improve their efficiency and competitiveness. Another way is to stimulate clustering as directed from a superior authority by applying state cluster policy techniques.

In the light of this, clusters (agglomerations) of enterprises, already demonstrating certain cluster properties and driving forces, should become objects of cluster policy. This proves that the identification of clusters should be done at the first stage of cluster policy.

Actually, the stage of identification is often ignored, clusters become objects of cluster policy with no regard to the stage of their development. The research of the regional cluster policy has been carried on the example of nine regions in the North East of the European part of Russia [1]. It has turned out that in most regions the choice of clusters as economic incentive objects was not based on a preliminary analysis of clusters. There were only two regions, clusters of which became the objects of economic policies based on the results of regional cluster identification (Kirov Region and Kostroma Region).

Localization Coefficient is one of the most known and simple techniques for identifying clusters. A standard (basic) version of Localization Coefficient is calculated by the number of employees and used in Porter's methodology [2] and in the European Cluster Observatory [3]. The technique is used independently [4] and as a part of complex techniques. A drawback with this technique is that it is applicable only to broad sectors (groups of narrow sectors). The reason is that official statistics on the number of employees for narrow sectors (segments of sectors) are not available.

Unlike the basic version of Localization Coefficient (LC), its modified version is calculated using different statistical indicators. This makes it applicable to narrow sectors (subsectors). There are many examples of research using modified Localization Coefficient for Russian conditions. Thus, for analysis of Russia's pilot clusters (a program to support regional clusters, which is being implemented by the Ministry of Economic Development of Russia), LCs were calculated by the number of business entities and sales revenues [5]. Kolchinskaya [6] analyzed the localization level of sectors on the example of St. Petersburg, using the following indicators: volume of shipped goods, number of business entities, balanced financial result (profit/loss), amount of investment, labor productivity, profitability. Prokopiev [7] carried out a research project on tax indicators of the Russian Forestry Complex - regional tax revenues and property tax revenues.

A comparison of the two techniques - the basic LC technique based on the number of employees and the modified LC technique - can be made using the example below [8]. Basic LCs were calculated for the Agriculture and Food sectors. Unfortunately, this technique did not allow identifying prototypes of agrarian clusters. A high the localization level was identified in both sectors only in three regions of Russia: Belgorod Oblast, Krasnodar Krai, and the Karachay-Cherkess Republic (LC threshold - 2.0, total sample size - 82 regions). 
- the factor of reaching of a critical mass by a group of neighbouring regions has been evaluated (the aim is evaluating the significance of size of a potential cluster on a national and global scale).

The data used for calculations has been taken from official website of the Federal State Statistics Service of Russia.

As an additional criterion, the size criterion (according to the methodology of the European Cluster Observatory) has been applied for the top 10 regions by the gross grain harvest of winter rye

\section{RESULTS}

Based on the Ranking of the Russia's regions by the gross grain harvest of winter rye (65 regions where winter rye is cultivated), a relevant map has been drawn (Figure 1). The map shows 26 regions with the highest gross harvests (Top $26)$. In total, $94 \%$ of the country's rye ( 2.5 million tonnes) is produced in these territories.

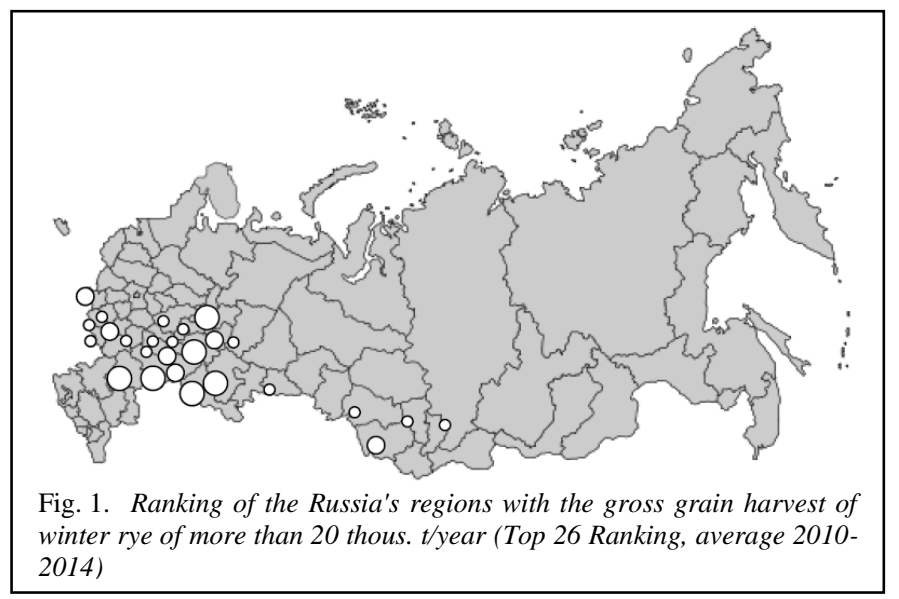

There are three clearly identified regions on the map where rye is cultivated for grain:

- the majority of the regions of the Volga Federal District, as well as the two neighboring regions Volgograd Region and Kurgan Region;

- Western regions of Russia (Bryansk, Voronezh, Oryol, Kursk, Tambov and Lipetsk Regions). Some of these regions adjoin the zone of rye cultivation in the Republic of Belarus;

- Several southern regions of Siberia (Altai and Krasnoyarsk Krai, Novosibirsk and Kemerovo Region).

At the same time, it is necessary to take into account the fact that the regions of Russia vary considerably in size of their economies and sectoral structures. As it was planned, the second ranking has been compiled based on the LCs of the rye grain production. Calculations have shown that the LC only for 18 regions (out of 65) turned out to be more than 2.0.

A comparison of the first and second ratings allows noting that not all regions of the Top 26 Ranking (Figure 3) entered the Top 2.0 Ranking. The Republic of Chuvashia and Samara Regions have ranked 19th and 21st, having the LC that is 
- LCs of rye grain production from 2.3 to 12.0 ;

slightly less than 2.0. Nizhny Novgorod, Lipetsk, Novosibirsk, Kemerovo and Perm Regions have showed the LC of 1.0 or less.

The results obtained make it possible to formulate several conclusions. Firstly, the gross harvest of grain indicator shows significant errors in identifying areas with high local content levels in rye grain production. The sample includes large industrial regions where rye is used in internal markets (e.g., Nizhny Novgorod and Perm Regions). Thus, the absolute size of industry should not be used as the main criterion when identifying clusters.

Secondly, the LCs made it possible to detect some unexpected phenomena in the considered sector. A group of Russian regions with very high LCs in rye grain production has been identified (from 3.5 in the Republic of Udmurtia to 12.0 in Kirov Oblast). It is important that these regions are also included in the Top10 Ranking of Russia regions by the absolute indicator - the gross harvest of rye grain.

As a result, it must be stated that the LC makes it possible to obtain more reliable results. Its modified version can be successfully applied to narrow sectors. It is possible to use more diverse statistical data in calculations.

Thirdly, in order to identify clusters, one should take into account the criterion of reaching a critical mass by the cluster (volume of production and exports). For this reason, agrarian clusters, apparently, will be located on the territories of several neighboring regions.

It follows that of the total set of 18 regions with high LCs of rye production not all regions have priority for a rye cluster. Firstly, these are the regions forming a compact territory, and, secondly, these are the regions with high LCs. Two of these conditions are not met for the group of western regions and for the group of regions of Siberia, despite the fact that these regions have very high LCs (e.g., Bryansk Oblast, $\mathrm{LC}=10.3$ ).

As a result, it turns out that the raw material base of the Russia rye cluster can make up 10 regions of the Volga Federal District. The map (see Figure 4) depicts location of these regions.

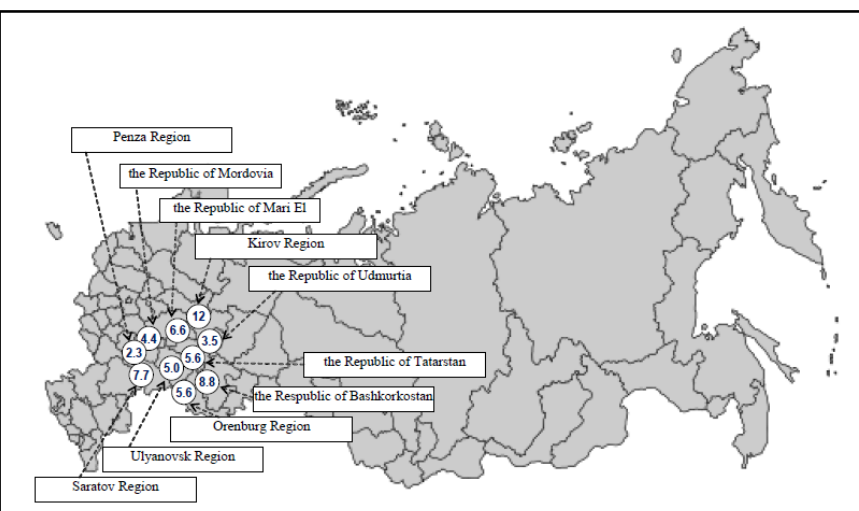

Fig. 2. Localization of the raw material base of the rye cluster in Russia (regions with the highest localization ratios for rye grain)

This group of regions has the following aggregate characteristics:
- 7 of 10 regions have ranked the Top 10 by the gross harvest of rye grain;

- $2 / 3$ of the gross harvest of rye grain;

- $80-90 \%$ of sales in interregional markets.

The idea of creating a cluster based on the territory of not one but several neighboring regions has objective grounds. Firstly, lands favorable for the cultivation of winter rye due to natural and climatic conditions are localized on the territory of several regions of the European part of Russia, or so-called "rye belt". Secondly, the cluster cannot be small a priori. Its size (in particular, the volume of production and export of products outside the cluster's border) should be sufficient to make the cluster noticeable in interregional and foreign markets. None, even the largest region of Russia, will not be able to provide the necessary gross harvest of winter rye grain.

International experience in clustering shows that creation of clusters on the territory of several regions is possible [14]. Many famous world agricultural clusters tend to be located on the territory of several regions of a country. For example, the dairy cluster is the most important sector of the Dutch economy. One third of the country's territory is allocated for dairy farming; more than half of raw milk produced there is used for cheese production. The cluster exports not only finished products but also equipment for the dairy industry. The Dutch company Lely is one of the world leaders in the production of milking robots. The Chilean wine cluster exports $75 \%$ of the products, mainly not raw materials but the final product - bottled wine. In 2002, exports to Latin America accounted for only 8\%, and more than $50 \%$ accounted for Europe, $44 \%$ for the US, Canada and Mexico.

A group of Russian researchers in the field of cluster theory and cluster policy considers the creation of interregional clusters as a possible option [15]. The emphasis is placed on the fact that physical distance between residents of the cluster in the conditions of the development of information technologies and communication facilities loses its relevance [16]. There are research projects on creating interregional clusters, for example, a project to create an interregional dairy cluster based on the Leningrad and Vologda Oblast $[17,18]$.

Hence, it appears that the hypothesis of the existence in the Volga region of a pronounced territorial concentration of raw material base for the rye cluster is confirmed. An area with a pronounced concentration of rye grain production with has been identified on the territory of the Volga Federal District of Russia. The idea of creating a cluster on the territory of several neighboring regions of Russia is also confirmed by international experience in agricultural clustering. 


\section{CONCLUSIONS}

A belief that the creation (nucleation) of clusters must occur naturally is formed based on the results of the discussion currently held in the scientific community on the relationship between evolutionary and artificial components in clustering. Enterprise groups that already show certain characteristics of clusters should be selected as objects of cluster policy. It is preferable that decisions to support specific clusters be based on the results of their identification (state, stages and dynamics of development).

Unlike the basic version of the LC, the modified LCs can be used to identify clusters for a wider range of sectors, including narrow sub-sectors. The technique is easy to use and not cost-consuming. In addition, it is recommended for use by regional governments when selecting clusters as objects of cluster policy.

Approbation of the technique in the context of rye cultivation sector has shown a pronounced localization of rye grain production on the territory of the Volga region. This localization can be considered as a raw material base of the rye cluster of Russia. Its basis can be comprised of at least 10 regions of the Volga Federal District. This group of regions provides $2 / 3$ of the gross harvest of rye grain in Russia and 80$90 \%$ of sales of rye grain in interregional markets. Further research is needed on the sectors involved in processing of rye grain (food and technical industries).

\section{References}

[1] Kostenko O.V. Cluster policy of Russian regions: content and comparative evaluation. Economics and Business Journal. 2016, 4(2), pp. 272-278.

[2] Porter M. The Economic Performance of Regions. Regional Studies. Vol.37.6\&7, pp. 549-578, August/October 2003.

[3] Danko G.V., Kutsenko E.S. Basic approaches to the identification of clusters in the region's economy. Problems of modern economics Journal. 2012, 1. URL: http://www.m-economy.ru/art.php?nArtId=3960.

[4] Tokhchukov R.R. Evaluation of prospects and opportunities for the formation of an agricultural cluster in the North Caucasus Federal District. Terra Economicus Publ. 2011, vol. 9, 3-3, pp. 130-133.

[5] Zemtsov S., Barinova V., Pankratov A., Kutsenko E. Potential high-tech clusters in Russian regions: from current policies to new points of growth. Foresight Publ. 2016, vol. 10, 3, pp. 34-52.

[6] Kolchinskaya E.E. Creation of clusters on the basis of manufacturing industries in St. Petersburg - an approach to identifying promising industries through localization coefficients. Economica Severo- Zapada Journal. 2011, 1, 10.

[7] Prokopiev E.A. To the question of the choice of data for determining the specialization of region. Durkerovskiy bulletin Publ. 2015, 4, pp. 236245.

[8] Kostenko O.V. Identification of agro-industrial clusters using localization coefficient. Theory management journal. 2017, 5, pp.88-93.

[9] Nikulina T.N. Healing power of rye. Achievements of science and technology. 2012, 6, pp. 5-7.

[10] Sysuev V.A., Kosolapov V.M., Fitsev A.I. Complex scientific research on winter rye - the most important national and strategic grain culture of the Russian Federation. Achievements of science and technology. APK Jounal. 2012, 6, pp. 8-11.
[11] Sysuev V.A., Kedrova L.I., Utkina E.I. Priority areas of research in solving the problem of multifunctional use of winter rye. Agrarian Science. Euro-Noth-West Journal. 2014, 6, pp. 4-8.

[12] Andreev N.R., Lukin N.D., Lapidus T.V., Borodina Z.M., Lapteva N.K., Kedrova L.I. Development of a comprehensive technology for processing rye for starch and sugary products. Achievements of science and technology. APK Jounal. 2012, 6, pp.79-81.

[13] Sysuev V.A., Lapteva N.K., Kedrova L.I., Philippova N.I., Andreev N.R. Formation of grain lots of winter rye with high starch content. Russian Agricultiral Science Buleetin. 2011. 3, 78

[14] Management System for the Parent Companies of the Innovative Territorial Clusters of the Russian Federation. Moscow. 2014, 250.

[15] Bocharov S.N., Lobova S.V. Interregional clusters: theoretical preconditions and development prospects. Altay Academy of economics and law Bulletin. 2012, 1, pp. 45-48.

[16] Lobova S.V., Ponkina E.V. Theoretical aspects of functioning of interregional clusters. Economic analysis: Journal of theory and practice. 2012, 17, pp 35-44.

[17] Alexsandr S. Kuznetsov. Russian Professor's meeting. Russian Journal of Physical Education and Sport. 2019, 14(1), pp. 17-22. DOI: 10.14526/2070-4798-2019-14-1-18-24

[18] Dibirov A.A., Stepanova G.I. Development Strategy of Agricultural Complex of the North Western Federal District of the Russian Federation. St. Petersburg, GNU SZNIESH Publ. 2013, 110. 